\title{
Food Insecurity Is Associated with Undernutrition but Not Overnutrition in Ecuadorian Women from Low-Income Urban Neighborhoods
}

\author{
M. Margaret Weigel, ${ }^{1,2,3}$ Rodrigo X. Armijos, ${ }^{1,2,3}$ Marcia Racines, ${ }^{3}$ and William Cevallos ${ }^{3}$ \\ ${ }^{1}$ Department of Environmental Health, Indiana University Bloomington School of Public Health, Bloomington, IN 47405, USA \\ ${ }^{2}$ Programa Prometeo, Secretaría Nacional de Educación Superior, Ciencia, Tecnología e Innovación, Quito, Ecuador \\ ${ }^{3}$ Facultad de Ciencias Medicas, Universidad Central del Ecuador, Quito, Ecuador \\ Correspondence should be addressed to M. Margaret Weigel; weigelm@iu.edu
}

Received 3 December 2015; Revised 28 January 2016; Accepted 22 February 2016

Academic Editor: Stephen Leeder

Copyright ( 2016 M. Margaret Weigel et al. This is an open access article distributed under the Creative Commons Attribution License, which permits unrestricted use, distribution, and reproduction in any medium, provided the original work is properly cited.

\begin{abstract}
Household food insecurity (HFI) is becoming an increasingly important issue in Latin America and other regions undergoing rapid urbanization and nutrition transition. The survey investigated the association of HFI with the nutritional status of 794 adult women living in households with children in low-income neighborhoods in Quito, Ecuador. Data were collected on sociodemographic characteristics, household food security status, and nutritional status indicators (dietary intake, anthropometry, and blood hemoglobin). Data were analyzed using multivariate methods. The findings identified revealed a high HFI prevalence (81\%) among the urban households that was associated with lower per capita income and maternal education; long-term neighborhood residency appeared protective. HFI was associated with lower dietary quality and diversity and an increased likelihood of anemia and short stature but not increased high-calorie food intake or generalized or abdominal obesity. Although significant progress has been made in recent years, low dietary diversity, anemia, and growth stunting/short stature in the Ecuadorian maternal-child population continue to be major public health challenges. The study findings suggest that improving urban food security may help to improve these nutritional outcomes. They also underscore the need for food security policies and targeted interventions for urban households and systematic surveillance to assess their impact.
\end{abstract}

\section{Introduction}

It is estimated that, by $2050,2.5$ billion persons or twothirds of the global population will be urbanites. Most of the increase is projected to occur in low- and middle-income populations [1,2]. As of 2014, $80 \%$ of the population of Latin America and the Caribbean (LAC) was already residing in urban centers [2]. Meeting the food and nutrition security needs of urban households in the LAC region and elsewhere is a growing worldwide public health challenge. Food and nutrition security is defined as follows: "when all people at all times have physical, social and economic access to food, which is consumed in sufficient quantity and quality to meet their dietary needs and food preferences, and is supported by an environment of adequate sanitation, health services and care, allowing for a healthy and active life" [3]. Dietary diversity or the ability to access a wide variety of different foods is central to this concept. Diets that include both a wide variety of foods across as well as within major food groups are associated with better nutrition and health outcomes $[4,5]$.

Urban centers in low- and middle-income populations operate as cash-based economies where food and other household needs are obtained primarily through local market systems [6]. For this reason, the food security situation of urban households tends to be more tightly linked to their income and purchasing power compared to rural areas where it is usually more dependent on food availability linked to local production $[7,8]$. Thus, having a steady and reliable source of cash income is critical since food costs alone may comprise as much as half or more of an urban household's 
monthly expenditures $[9,10]$. Food security also is dependent on a consistent supply of foods in the urban marketplace at prices that are low enough for households to afford.

At the household level, food insecurity is characterized by the "limited or uncertain availability of nutritionally adequate and safe foods or the limited or uncertain ability to obtain foods by socially acceptable means" $[11,12]$. Prior studies have documented that household food insecurity (HFI) which is acute or severe is associated with wasting and other indicators of severe undernutrition [12]. However, less severe episodic or cyclical HFI may also adversely impact the nutrition and health of women and other household members [12]. One of the ways in which it may do so is by affecting dietary quality and diversity. The findings from the few studies that have reported on the topic in LAC region countries, that is, Colombia and Trinidad and Tobago, suggest that mildmoderate episodic or cyclical food insecurity is associated with less frequent consumption of fruits, vegetables, dairy products, meat, and fish [13-16]. Such nutrient-dense foods are usually more costly pound-for-pound than lower quality items (e.g., white rice, noodles, bread, cassava, and potatoes).

Some recent studies also have implicated HFI in a higher prevalence of anemia $[17,18]$ and short stature in Ecuadorian [19] and Guatemalan women [18]. Anemia is a major public health issue in the LAC region because of high prevalence [20] and well-documented association with maternal mortality and morbidity, adverse maternal-perinatal outcomes, and diminished physical work capacity [20-22]. Likewise, short stature in adult women is an important public health concern due to its role in obstructed labor due to cephalopelvic disproportion and its association with reduced work capacity and economic productivity [23]. In addition, the offspring of short mothers are more likely to grow up stunted themselves and to produce stunted children who are at risk for future obesity $[23,24]$.

It has been hypothesized that HFI may promote weight gain and overweight/obesity in women through one or more complementary biobehavioral mechanisms involving diet, basal metabolism, stress hormones, and/or physical activity $[12,25-28]$. However, the dietary and anthropometric data in support of the controversial "food insecurity-obesity hypothesis" is inconsistent. Studies conducted in high-income countries such as the US and Canada $[12,25,28]$ and several LAC region countries including Colombia [13-15], Brazil [29, 30], Mexico [31], and Trinidad and Tobago [16] differ as to whether HFI promotes consumption of high-calorie foods, weight gain, and overweight/obesity in women and if so whether the direction of association is positive or negative.

Ecuador is one of a number of LAC region countries about which few HFI data have been published. Two-thirds of the residents of this rapidly urbanizing middle-income Andean country live in urban areas [32]. It has a welldeveloped agricultural sector, has an efficient food transportation system, and produces a wide variety of fresh fruits, vegetables, seafood, dairy products, meats, eggs, and other foods throughout the year. It also is a major food exporter and is food secure at the national level. Ecuador has made significant improvements in its economic and social situation during the past seven years. However, structural inequities still exist that decrease the access of impoverished households to sufficient nutritious food and other resources.

Data collected from the 2012 ENSANUT-ECU national health and nutrition survey strongly suggest that the Ecuadorian population is undergoing nutritional and epidemiologic transition. The survey findings indicate that the diet is becoming "westernized" with more refined grains, sugar, and fat $[33,34]$. Unenriched white rice accounts for one-third of total dietary energy and African palm oil, a highly saturated cooking oil, accounts for $20 \%$ of lipids in the Ecuadorian diet. The survey results also indicate that energy-dense convenience, snack, and fast food intake by adolescents is common [34]. In addition, retail sales of ultraprocessed, sweetened beverages including soda pop, sports/energy drinks, and fruit juice/nectar drinks have steadily increased over the past 10 years [35]. The ENSANUT-ECU survey also reported low fruit and vegetable consumption among adults, averaging less than half of recommendations. Forty-five percent of Ecuadorian adults are reported to have low physical activity levels or are sedentary [33]. Similar to many other LAC countries, overweight and obesity often coexist with micronutrient malnutrition and stunting even within the same household or individual $[33,34]$. Gastrointestinal, respiratory, vectorborne, and other infectious diseases remain common but obesity-related chronic diseases, that is, hypertension, heart disease, and diabetes, now rank as the top three causes of adult mortality [36].

Ecuadorian women and their children are particularly vulnerable to the double burden of undernutrition and overnutrition [19, 33, 34]. The prevalence of inadequate dietary micronutrient intake in women is high including vitamin A (88\%), iron (78\%), and zinc (11\%) [33]. Anemia is the seventh leading cause of disability in the country affecting approximately $15 \%$ of women. Fifty-six percent also have zinc deficiency [33]. Approximately two-thirds of Ecuadorian women are overweight or obese $[19,33,34]$ and one-sixth have short adult stature indicative of prior growth retardation during childhood or adolescence [19].

Quantitative data describing HFI and its correlates in the Ecuadorian population are scant. They include two small surveys conducted in rural farming communities in 2006 [37] and 2012 [38] and a 2014 analysis of household food insufficiency collected during the 2004 ENDEMAIN national reproductive health survey from 10,784 households with women aged 15-49 years [19]. The findings from these three surveys suggest that HFI seems to be relatively common and associated with lower food stores of meats, vegetables, legumes, and edible oils [37], reduced household expenditures on micronutrient-rich animal and plant foods [19], or lower intakes of animal protein foods [38]. The ENDEMAIN survey did not identify any association between HFI and excess body weight but did find that short stature was more prevalent among adult women [19].

It is unclear whether the limited findings from the aforementioned surveys are applicable to present day urban residents. Two of the three were conducted in rural farming households, both had very small sample sizes, that is, 52 households [37] and 113 households [38], and in one of these most of the participants were 60 years or older [38]. 
In addition, the data for two of the studies were collected around a decade ago when Ecuador was most likely in an earlier phase of the nutrition transition [19,37]. Furthermore, although the 2012 study collected dietary intake data, it did not report on other nutritional indicators [38].

The major objective of the present study was to investigate the association of HFI with dietary, biochemical (blood hemoglobin levels), and anthropometric indicators of nutritional status in women from low-income households in a major urban center (Quito) in Ecuador. The working hypotheses were as follows: (1) due to their limited resources, food insecure women would be more likely than their food secure counterparts to report poorer quality and less diverse diets which would be lower in rich food sources of micronutrients and animal protein; (2) they also would be more likely to have anemia due to the poorer micronutrient content of their diets; (3) they would be more likely to show evidence of past stunting in the form of short adult stature caused by long-term economic inequities that promote food insecurity; and (4) they would more frequently consume high-calorie foods that promote excess body weight for reasons of lower cost, high-satiety characteristics, or other biobehavioral mechanisms.

\section{Methods}

2.1. Description of the Study Population. The study was conducted in Quito, the administrative and political capital of Ecuador which is situated in the Andes Mountains at average elevation of $2950 \mathrm{~m}$ above sea level (range: 500$4790 \mathrm{~m}$ ) [39]. It is the second largest city in the country with 2.4 million residents and nearly one-fifth of the country's total population [40-42]. More than one-third (35\%) of city residents are internal migrants, most of whom come from rural areas of highland provinces in northern and central Ecuador [43]. Quito also is one of the main destinations for political refugees and economic refugees from Colombia, Peru, Chile, Cuba, and Spain [44]. Official government figures indicate that, from 2010 to 2014, the proportion of Quito residents living in poverty ranged from $8.9 \%$ to $10.3 \%$; extreme poverty affected 3-3.4\% [45].

2.2. Study Site and Participants. The present work formed part of a larger investigation of the food, nutrition, and health issues of women and children from low-income urban neighborhoods. The survey study was conducted during the months of May-August in 2010, 2011, 2012, and 2014 in neighborhoods located in five Quito neighborhood sectors (Chillogallo, Cotocollao, El Dorado, El Camal, and Los Chillos). A nonprobabilistic sample of 794 adult female heads of households and their minor children aged 6-12 years were recruited through neighborhood public elementary schools and community health centers. The selection of mothers and their children in this age group was initially informed by our outreach work with local community partners from public elementary school parents and administrators and local medical professionals in the low-income Quito neighborhoods. They were concerned about the food, nutrition, and health of the children and their families. They were especially worried that many children on the vespertino (afternoon) school schedule were arriving at school without having eaten breakfast or lunch.

The face-to-face interviews with the mothers collected data on household food security status, sociodemographic characteristics, food intake, anthropometric indicators, and blood hemoglobin. To be eligible for study inclusion, prospective participants were required to be the mother of at least one school-aged minor child (6-12 years) who lived in the same household. They were also required to be a permanent resident of their current community and not to have any sensory or developmental conditions impeding their ability to understand and respond to questions. In cases where the mother was not living in the home due to divorce, death, or migration, the de facto female head of household (e.g., grandmother, aunt, and stepmother) living in the home participated. Study approval was obtained from institutional review boards at the University of Texas at El Paso and Biomedical Research Institute at the Central University of Ecuador. All of the women participants provided their informed written consent. Study participants received oral and written interpretations of their anthropometric, blood pressure, and laboratory screening results and as appropriate were given written referrals for follow-up health care.

\subsection{Data Collection}

2.3.1. Household Food Security. The food security status of participant households was examined using the US Household Food Security Survey Module (HFSSM) Spanish version [46], adapted for use in Ecuador. The HFSSM was selected for use in the urban Quito group because it had been previously validated in rural Ecuadorian households [37] and when we first began our study, the Latin American and Caribbean Food Security Scale and other HFSSMderived instruments were still undergoing development and testing and were not yet widely available. However, since the instrument had not been previously validated for urban households in Ecuador, we also decided to examine its internal validity, reliability, and other psychometric properties. Our findings which are detailed in the attached Supplemental File (see Supplementary Material available online at http://dx.doi.org/10.1155/2016/8149459) indicated that the performance of the language-adapted HFSSM was consistent with the theoretical framework of household food insecurity as a managed process and exhibited good validity and reliability.

The 18 questions contained in the instrument covered a spectrum of participant-reported household food access problems ranging from worry over running out of food to food deprivation in children. They included ten questions specific to adults or the household in general and eight others specific to minor children $(<18$ years) living in the household [47]. Answers were classified as affirmative if the adult woman participant responded "yes," "often," "sometimes," "almost every month," and "some months but not every month" to the various questions. Affirmative responses to the 18 items were summed to construct the raw score which was used to classify 
households as food secure (score: $0-2$ ) or as food insecure, that is, with low food security (score: $3-7$ ) or very low food security (score: 8-18) [47]. Households classified with low food security reported reduced quality, variety, or desirability of diet with little or no indication of reduced food intake while those with very low food security reported multiple indications of disrupted eating patterns as well as reduced food intake [47].

2.3.2. Participant and Household Characteristics. Data were collected during face-to-face interviews with the 794 adult female participants. The data collected on the characteristics of the participants and their households included age, education, marital status, pregnancy status, occupation, current employment status, monthly household income, birthplace, place of residence, neighborhood location, length of residence in current neighborhood, and family size.

\subsection{Nutritional Status Indicators}

2.4.1. Self-Reported Dietary Quality. The participants were asked to rank the overall quality of their diet over the past 12month period using a 5-point Likert scale where the possible responses ranged from excellent to poor [48]. Their responses were regrouped as fair/poor versus other for the statistical analysis.

2.4.2. Food Frequency Questionnaire. A standard format food frequency questionnaire (FFQ) was used to collect data from participants on their usual intake of commonly consumed foods and beverages during the prior 12 months [49]. The specific foods and beverages contained in the FFQ were selected based on 24-hour dietary recall studies previously conducted by the authors in Quito and other populations in northern Ecuador and after additional consultation with local experts and key informants. The FFQ was piloted at an urban public health clinic in a low-income Quito neighborhood and then we refined the items as necessary. The FFQ food frequency categories ranged from never or less than once per month to 4-6 times per day. The response frequencies were converted into average weekly intakes for the analyses. The FFQ items were classified into major 11 groups: cereals, meats, eggs, milk/milk products, legumes/nuts/seeds, vegetables, fruits, fish/other seafood, white tubers/roots, sweets, and oils/fats (i.e., cooking oil, margarine, butter, and mayonnaise). These food group classifications followed the Food and Agricultural Organization (FAO) guidelines [50]. Because of interest in the association of food insecurity with energy-dense foods and obesity, we also added an additional 12th group consisting of high-calorie, high-fat, fried and salty snack and convenience foods obtained from street vendors, purchased from stores, or cooked at home. In addition, we created additional groups in order to examine the relationship of food security status with the intake of specific foods rich in retinol precursor carotenoids (i.e., dark leafy green vegetables, certain tubers, and fruits), retinol (i.e., egg yolks, fortified milk/milk products), and heme iron (i.e., flesh meats, fish/seafood) as well as animal protein foods (i.e., flesh meats, fish/seafood, eggs, milk, cheese, and yoghurt) [50].

2.5. Anthropometric Indicators. Data on body weight were obtained by weighing nonpregnant participants to the nearest kilogram without shoes or heavy clothing on a calibrated electronic balance (Detecto, Webb City, MO). The scale was recalibrated after each weighing. A portable stadiometer (Seca NA, Chino, CA) was used to measure standing height without shoes, hats, or other headwear. Complete sets of weight and standing height data were obtained from 703 participants to use in the calculation of body mass index (BMI), defined as weight $(\mathrm{kg}) /$ height $\left(\mathrm{m}^{2}\right)$. Participants with BMIs of $<18.5,18.5-24.9,25-29.9$, and $\geq 30$ were classified, respectively, with underweight, normal weight, overweight, and obesity [51]. We were able to obtain waist circumference measurements on 706 nonpregnant participants to assess abdominal obesity. Waist circumference was measured with a semiflexible anthropometric measuring tape (Seca NA, Chino, CA). Participants with waist circumferences measuring $>88$ centimeters were classified with abdominal obesity following NHLBI/AHA recommendations [52]. Standing height measurements were used to classify short stature $(<145 \mathrm{cms})$ in women participants aged $\geq 20$ years [23]. We included both nonpregnant and pregnant women in these analyses. The rationale for restricting the analysis of short stature to women who were 20 years or older was to exclude adolescents who may not had yet achieved their final adult height [23].

2.6. Blood Hemoglobin. A sample of fingertip capillary blood was collected from participants for the purpose of measuring their blood hemoglobin concentrations. The blood samples were analyzed by the HemoCue ${ }^{\circledR}$ photometer (Model 201, HemoCue Inc., CA). Anemia manifested as low hemoglobin was used as a proxy indicator for iron deficiency in this study. Hemoglobin values were used to classify anemia according to established hemoglobin concentration cutoff-points [53]. The anemia classification categories for nonpregnant women were as follows: $11.0-11.9 \mathrm{~g} / \mathrm{dL}$ (mild), $8.0-10.9 \mathrm{~g} / \mathrm{dL}$ (moderate), and $<8.0 \mathrm{~g} / \mathrm{dL}$ (severe). The anemia classification categories for the 16 pregnant participants in the study were as follows: $10-10.9 \mathrm{~g} / \mathrm{dL}$ (mild), $7.0-9.9 \mathrm{~g} / \mathrm{dL}$ (moderate), and $<7.0 \mathrm{~g} / \mathrm{dL}$ (severe). The five Quito neighborhoods in which the participants lived ranged in altitude from 2453 meters (Los Chillos) to 3068 meters (Chillogallo) above sea level [54, 55]. The measured hemoglobin concentrations were adjusted for the altitude of participant residences following WHO [53] recommendations.

2.7. Data Analysis. The study data were analyzed using the IBM-SPSS statistical software, version 23 (IBM Corp.). The descriptive data are presented as number (\%) or mean \pm SD. Multinomial logistic regression was used to investigate the association of respondent and household characteristics identified in the initial analyses with the three HFI groups. This analytic method also was used to examine the association of HFI with overweight and obesity. Poisson regression 
with robust variance estimation was used to examine the association of HFI with iron-deficiency anemia, short adult stature, and abdominal obesity. The multivariate analyses adjusted for potential confounders including household per capita monthly income, maternal education, current Quito neighborhood residence (location) and length of residency, and data collection year. The data from the multinomial and Poisson regression analyses are presented as unadjusted and adjusted prevalence ratio (PR) estimates with $95 \%$ confidence intervals. Differences in the average number of different food group items consumed weekly by the study households and their average weekly consumption frequency of specific food groups were assessed using a general linear model adjusted for covariates in the multivariate analyses. $p$ values $<0.05$ were considered statistically significant.

\section{Results}

3.1. Participant and Household Characteristics. Table 1 displays the characteristics of the 794 women participants and their households.

3.2. Household Food Security. Eighty-one percent of the women participants reported that their households had experienced food insecurity sometime during the past 12 months. Forty-one percent $(n=325)$ reported low food security and $40 \%(n=317)$ very low food insecurity. Table 2 shows the results of the analyses indicating that monthly per capita income and years of participant formal education were inversely associated with HFI. In contrast, participants who had lived in the same Quito neighborhood for $50 \%$ or more of their lifetime were much less likely to live in a household with low or very low food security. After adjustment for the other model covariates, the contribution of participant age, marital status, and housewife occupation was no longer evident.

\subsection{Dietary Indicators}

3.3.1. Self-Reported Dietary Quality. Twenty-eight percent $(n=91)$ and $59 \%(n=186)$ of women participants living in low or very low food security households, respectively, ranked the quality of their diets over the previous 12 months as only fair to poor compared to $14.6 \%(n=22)$ of those who were food secure. Participants living in household with low food security (adjusted PR $=1.94 ; 95 \% \mathrm{CI}=1.27,2.96 ; p=$ 0.0001 ) or very low food security (adjusted $\mathrm{PR}=4.03 ; 95 \%$ $\mathrm{CI}=2.71,5.99 ; p=0.0001)$ were, respectively, nearly two and three times more likely than their food secure counterparts to report that their diet had been only fair to poor during the past 12 months.

3.3.2. Dietary Diversity: Variation across and within Food Groups. Table 3 indicates that food insecure women, especially those from households with very low food insecurity affected with very low food security, reported generally less diverse diets during the previous 12-month period as measured by the amount of variation both across and within the 12 major food groups as well as within certain plant and
TABLE 1: Sociodemographic characteristics $(n=794)$.

\begin{tabular}{|c|c|}
\hline Characteristics & $\begin{array}{l}\text { Mean } \pm \text { SD } \\
\text { Number }(\%)\end{array}$ \\
\hline $\begin{array}{l}\text { Monthly per capita household income (\$US } \\
\text { dollars) }\end{array}$ & $110 \pm 104$ \\
\hline$\leq \$ 50 /$ month & $173(21.9)$ \\
\hline \$51-99/month & $262(33.1)$ \\
\hline$\$ 100-149 /$ month & $206(26.0)$ \\
\hline$\geq \$ 150 /$ month & $150(19.0)$ \\
\hline Education (years) & $8.0 \pm 3.8$ \\
\hline$<6$ years & $141(17.8)$ \\
\hline $6-9$ years & $386(48.6)$ \\
\hline$\geq 10$ years & $267(33.6)$ \\
\hline Age (years) & $34 \pm 10.6$ \\
\hline$<30$ years & $344(43.3)$ \\
\hline $30-44$ years & $327(41.2)$ \\
\hline$\geq 45$ years & $123(15.5)$ \\
\hline \multicolumn{2}{|l|}{ Marital status } \\
\hline Legally married & $235(29.6)$ \\
\hline Common law union & $312(39.3)$ \\
\hline Single, never married & $178(22.4)$ \\
\hline Separated/divorced/widowed & $69(8.7)$ \\
\hline Occupation (full-time housewife) & $417(52.5)$ \\
\hline \multicolumn{2}{|l|}{ Neighborhood location } \\
\hline Chillogallo & $162(20.4)$ \\
\hline Cotocollao & $255(32.1)$ \\
\hline El Dorado & $212(26.7)$ \\
\hline El Camal & $102(12.8)$ \\
\hline Los Chillos & $63(7.9)$ \\
\hline Quito birthplace & $348(43.8)$ \\
\hline $\begin{array}{l}\text { Long-term residency in current neighborhood } \\
(\geq 50 \% \text { of lifetime) }\end{array}$ & $483(60.8)$ \\
\hline Household size (number of members) & $4.6 \pm 1.6$ \\
\hline 2-3 members & $174(21.9)$ \\
\hline 4-5 members & $447(56.3)$ \\
\hline$\geq 6$ members & $173(21.8)$ \\
\hline Pregnancy status: currently pregnant & $16(2.0)$ \\
\hline
\end{tabular}

animal food groups that are high in certain micronutrients and animal protein. However, they did not disproportionately consume a greater number of items from food groups considered to be energy-dense and micronutrient poor (e.g., sweets, fried and salty snack/convenience/fast foods).

As the adjusted analysis results displayed in Table 3 indicate, women from households with very low food security consumed a slightly lower average number of food groups compared to those from homes that were food secure or had low food security. However, this difference was small, that is, only two-tenths of a percent.

Table 3 also displays the findings of the adjusted analyses indicating that as compared to food secure women those with low and very low food insecurity had significantly reduced 


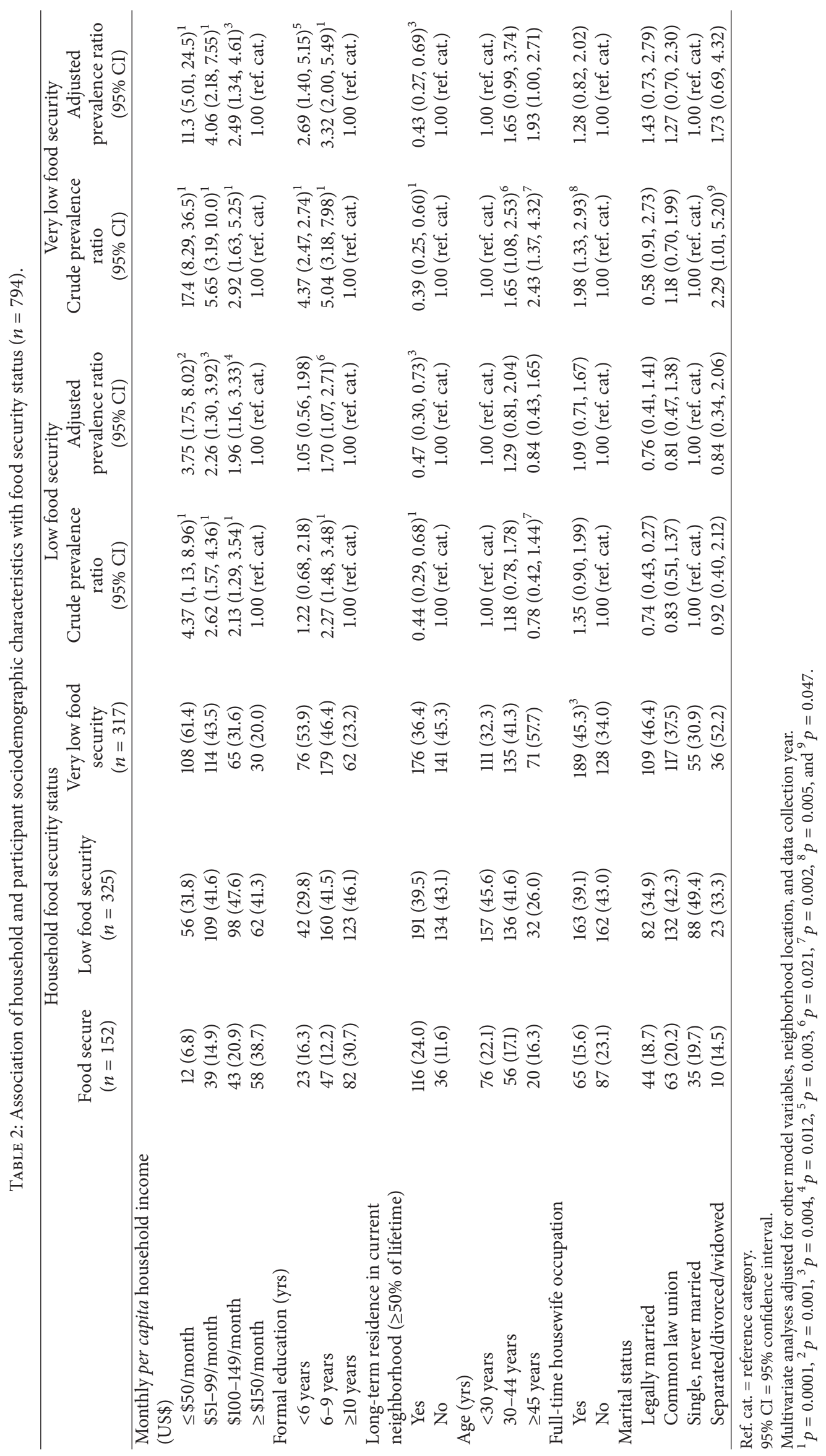




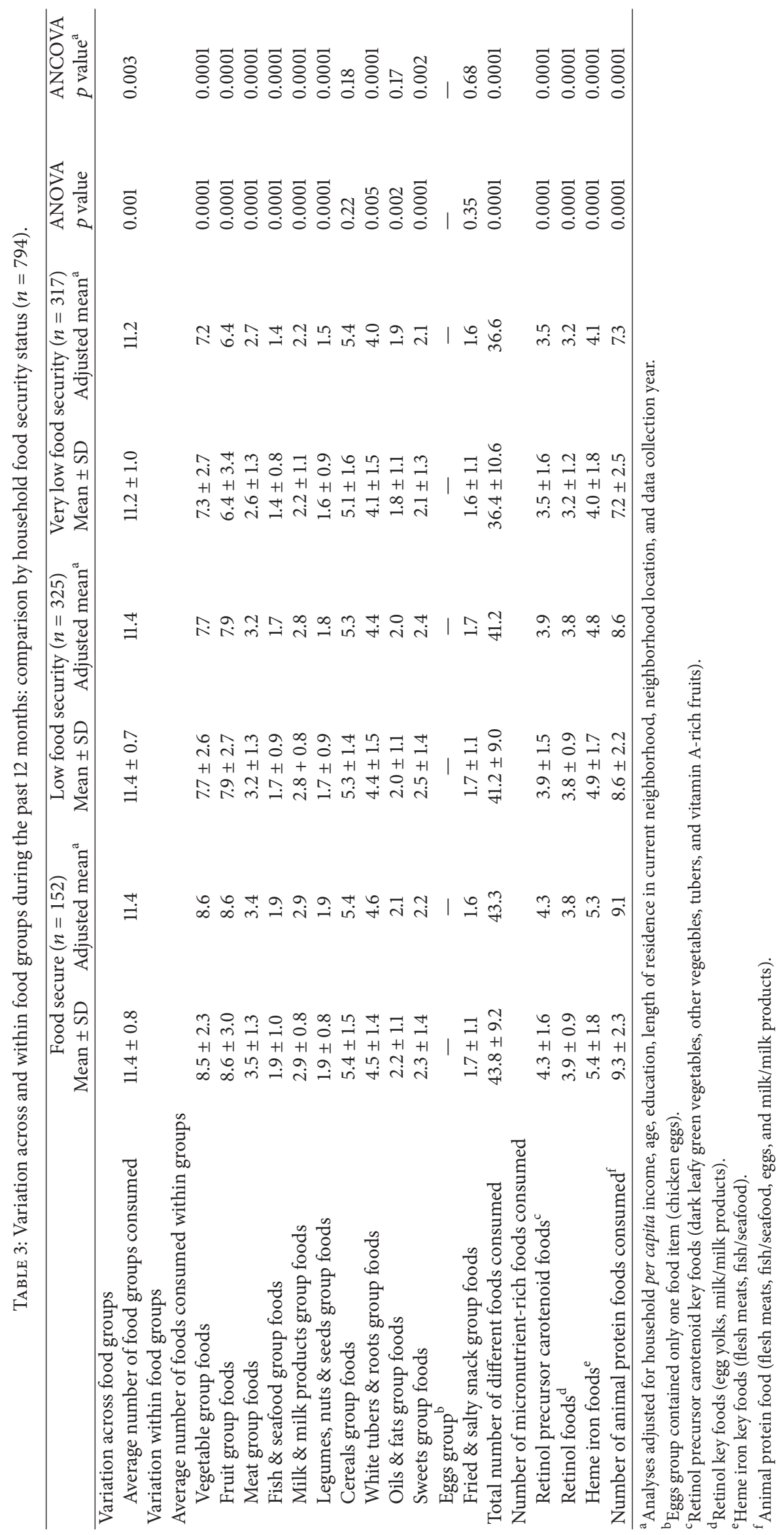


average intakes of different foods from the vegetable, fruit, meat, fish/seafood, milk/milk products, legumes/nuts/seeds, and white tubers/roots groups. The results also indicated that women with very low food security reported consuming fewer different items belonging to the sweets group compared to those who were food secure. In contrast, those from low food security households reported ingesting a slightly increased number of sweet foods. However, no statistically significant differences were identified in the mean number of different cereals, oils/fats, and fried and salty snack/convenience/fast food items reported as consumed by participants from the three household food security groups.

Food insecure women, especially those from household with very low food security, also appeared to have less diverse diets as indicated by the average number of different foods they reported consuming over the previous 12 months that were rich in retinol, retinol precursor carotenoids, heme iron, and animal protein.

3.3.3. Food Consumption Frequency. Table 4 shows that participants from food insecure homes, especially those with very low food security, reported lower average weekly consumption of fruits, meats, fish/seafood, and milk/milk products compared to their food secure counterparts in the past 12 months. Those with very low food security also indicated that they had eaten vegetables less frequently than women living in households that were either food secure or having low food security. In contrast, no statistically significant differences were identified among participants from the three household food security groups regarding average weekly consumption of eggs, legumes/nuts/seeds, cereal, white tubers/roots, lipid/fats, sweets, and snack/convenience/fast foods. The adjusted analysis findings, displayed in Table 4, also indicate that participants from food insecure homes, particularly those with very low food security, reported less frequent weekly consumption of micronutrient-rich (i.e., retinol, carotenoids, and heme iron) and animal protein foods.

No major differences were found in the proportion of women participants who reported that they had consumed sweet foods or fried and salty snack/convenience/fast foods at least once a week on average, during the past 12 months. Figure 1 shows that approximately three-quarters of the women reported that they had regularly consumed fried/salty fast foods (e.g., French fries, hot dog slices, fritada (pork), hamburgers, empanadas, and ripe plantains) and more than one-half sugary carbonated beverages or potato chips at least once a week in the past year. The weekly consumption of the other energy-dense foods and beverages ranged from 19 to $40 \%$ (Figure 1). However, the adjusted analysis results did not identify any statistically significant differences in the consumption frequency of the food and beverage subgroups (data not shown).

3.4. Blood Hemoglobin and Anemia. Blood samples from 595 participants were available for the hemoglobin analyses. The altitude mean adjusted hemoglobin concentrations of women from households with low $(12.7 \pm 1.6 \mathrm{~g} / \mathrm{dL})$ or very low food security $(12.3 \pm 1.7 \mathrm{~g} / \mathrm{dL})$ were significantly reduced compared to those from food secure $(13 \pm 1.4 \mathrm{~g} / \mathrm{dL})$ households $(F=7.5$; $p=0.001)$.

Slightly more than one-third (34.8\%) were classified with anemia using the World Health Organization (WHO) criteria [56]. All of the anemia cases were classified as "mild" except for 13 (2.2\%) who had moderate anemia and one who had severe anemia. Table 5 displays the results of the adjusted analysis indicating that the prevalence of anemia among women living in households with more severe food insecurity, that is, very low food security, was nearly doubled compared to those who were food secure. However, low household food security, a milder form of food insecurity, was not associated with anemia. We were unable to analyze the association of household food security status with anemia severity. There were too few cases of moderate and severe anemia so the amount of available statistical contrast was too low to produce meaningful prevalence ratio estimates for the three anemia severity groups. However, as the WHO [56] has noted, "mild anemia" is a misleading term since iron deficiency is already advanced by the time anemia becomes detectable [56].

3.5. Anthropometric Indicators. No statistically significant differences were identified in the average BMIs of nonpregnant women from low $(27.5 \pm 13)$ and very low food security $(28 \pm 15)$ households compared to those living in food secure $(27 \pm 5)$ homes $(p=0.79)$. Based on their BMIs, $1 \%$ were classified as underweight and $38 \%$ as normal weight. In contrast, nearly two-thirds had BMI indicative of overweight $(38 \%)$ or obesity $(23 \%)$. More than half $(53 \%)$ also had waist circumferences $>88 \mathrm{~cm}$ indicating abdominal obesity. However, as Table 6 shows, food insecure participants were not more likely than those who were food secure to be overweight or obese nor were they more likely to have abdominal obesity (Table 6).

Participant height averaged $1.51 \pm 0.06$ meters (range: $1.2-$ $1.8 \mathrm{~m})$. Fifteen percent of the women aged $\geq 20$ years were classified with short adult stature $(<1.45 \mathrm{~m})$. Women from households with very low food security, but not less severe low food security, were more likely to show evidence of short adult stature although the strength of this association became marginal after adjustment for covariates.

\section{Discussion}

The present work is only one of three quantitative studies to investigate household-level food insecurity in Ecuador using an experienced-based, validated instrument and is the only one to specifically focus on urban women. In this study, HFI prevalence was high (81\%) and associated with several undernutrition indicators suggesting micronutrient malnutrition in the urban Quito participants. However, it was not associated with a greater consumption of energydense foods and beverages nor with excess body weight or abdominal fat.

The prevalence of HFI in the urban Quito sample while slightly lower than figures quoted for two Ecuadorian rural highland farming groups [37, 38] was still substantial, affecting eight of every ten of the low-income households. 


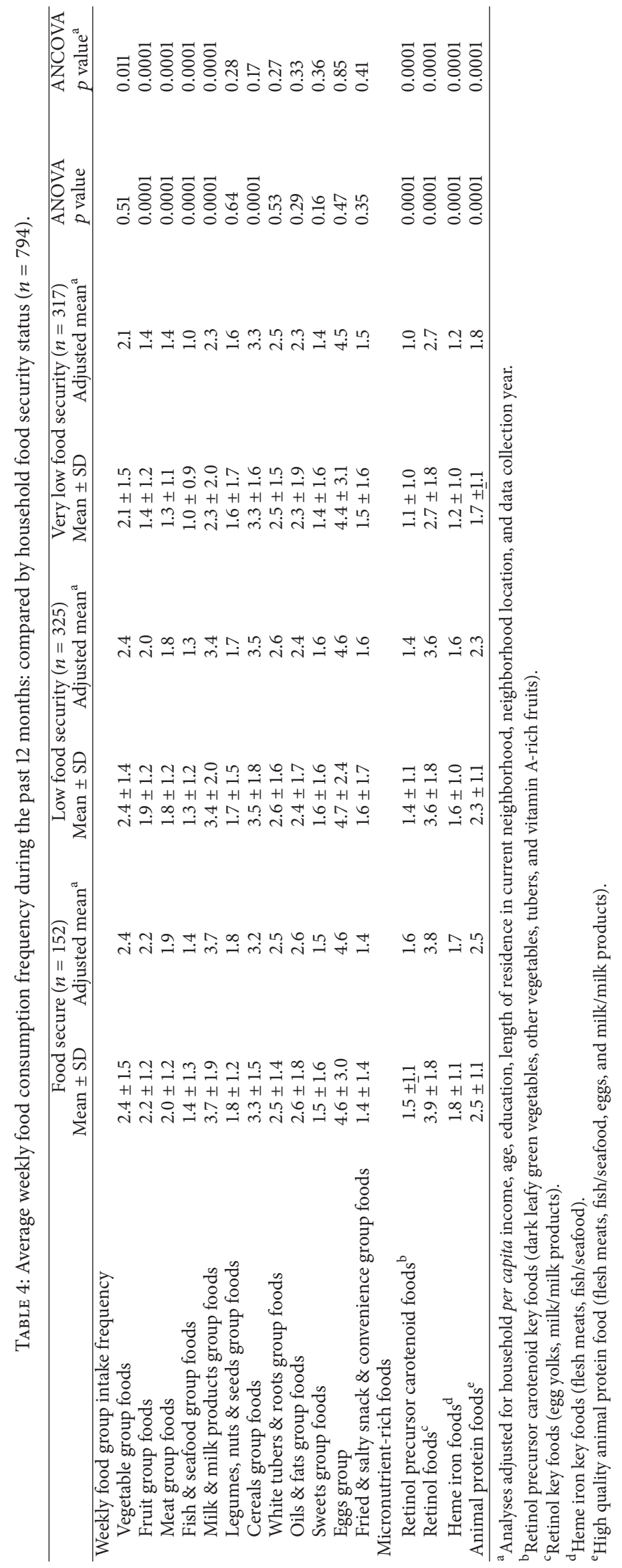




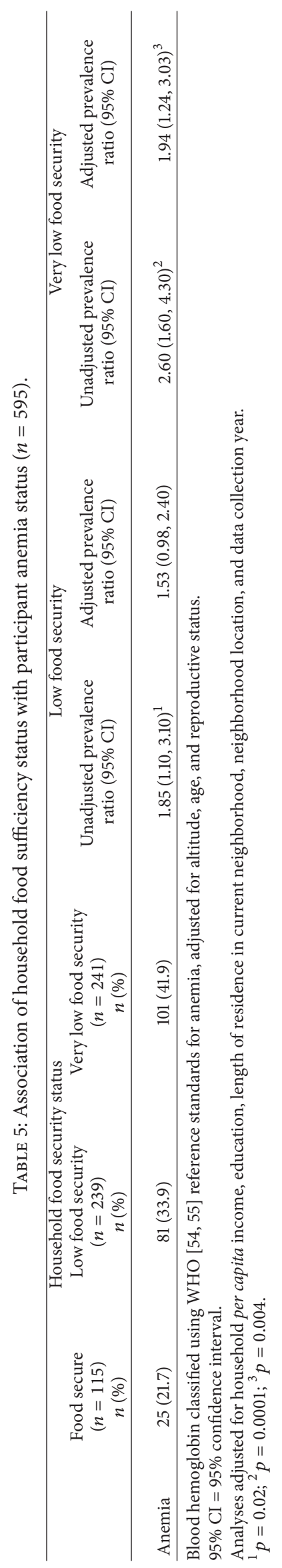




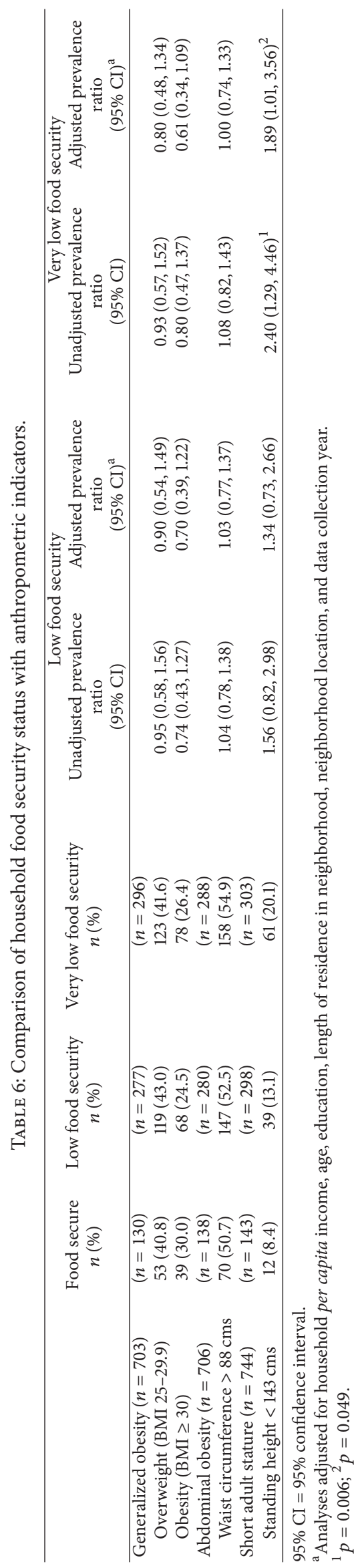




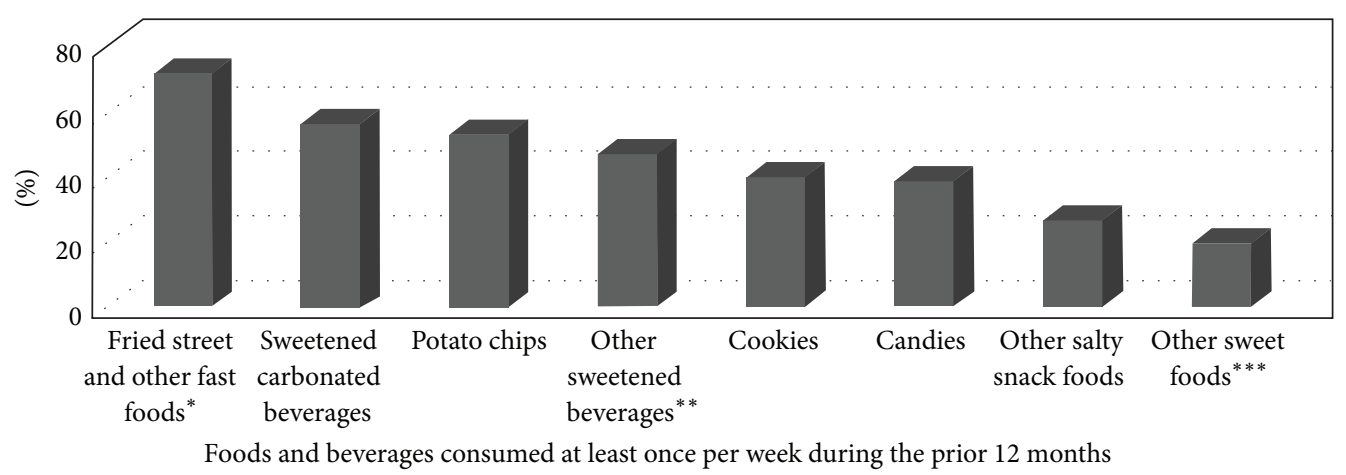

FIGURE 1: Reported weekly average consumption of sweet and fast/convenience/snack foods and beverages $(n=794) .{ }^{*}$ Included items such as French fries, salchipapas (fried hot dog slices with French fries), fritada (fried pork pieces), empanadas, ripe plantains, and other fried foods. ${ }^{* *}$ Including items such as energy drinks, boxed fruit juice and nectar drinks, and other sugary processed beverages. ${ }^{* * *}$ Included items such as donuts, cakes, meringues, jello, frozen confections, and other sugary foods.

It does not seem unreasonable to suggest that if HFI is this common in the capital city, it is likely that it exists at the same or even higher levels in other Ecuadorian urban centers where poverty rates are even greater [45].

As has been reported for Ecuador and other LAC region groups, as household income $[15,19,57]$ and women's formal education declined $[19,29,56]$, HFI increased. In contrast, long-term residence in the same Quito neighborhood appeared to be protective against HFI even after controlling for income and education. We surmise that this may be due to greater access of long-term residents to cheaper food outlets or better access to social safety net programs and social networks upon whom they can rely for food or cash gifts, loans, or trade. This factor should be explored in greater detail in future studies of urban HFI.

The finding that women living in food insecure homes, especially those with very low food security, had lower quality and less diverse diets is of particular concern since the consumption of a wide variety of good quality foods across and within major food groups is important for preconception, prenatal, and postnatal nutrition as well as overall health. Eating a diverse diet also ensures the presence of beneficial phytochemicals, promotes balance among nutrients that influence micronutrient absorption and utilization [20,58], and reduces the risk for multiple micronutrient deficiencies [22].

The present findings also concur with emerging evidence linking more severe HFI to an increased prevalence of anemia in Mexican [17] and Guatemalan women [18]. In this study, the reduced levels of diversity both across and within food groups that characterized the diets of food insecure women appeared to be reflected in their higher prevalence of anemia based on the results of a post hoc analysis we conducted. Specifically, anemia was more common among women whose diets contained fewer different foods overall $(p=0.02)$ and those that had fewer foods containing heme iron $(p=0.03)$ and other animal and plant foods with nutrients that can act to enhance iron absorption and metabolism, that is, retinol ( $p=0.003)$, carotenoids $(p=0.01)$, and ascorbic acid (fruits) $(p=0.003)$.
The results also concur with those of other recently published studies from Ecuador [19] and Guatemala [18] indicating that the prevalence of short adult stature was higher among women living in more severely food insecure households. This suggests that their families may have also suffered from HFI and so they were probably exposed to undernutrition during critical growth periods during their childhood or adolescence. These findings infer that interventions focused on improving household food security have the potential to also improve dietary diversity and micronutrient status which, in turn, could reduce the risk for nutritional anemias and stunting.

The data on the intake frequency of fast, snack, and convenience and other high-calorie foods and beverages reported by the adult women in our study are consistent with those also noted for adolescents in the recent ENSANUTECU survey [33]. However, the study data failed to support the hypothesis that HFI would be associated with the more frequent consumption of these types of foods and beverages. Our results concur with the small handful of studies published on this topic in LAC region countries [13-16]. The high (61\%) prevalence of overweight/obesity identified among the participants is consistent with figures recently published for other Ecuadorian women $[19,33]$. The study data, however, failed to support the hypothesis that HFI would be associated with excess body weight or abdominal fat in the urban Ecuadorian women. Although these results are similar to those noted for Ecuadorian women in the ENDEMAIN study [19] and for those in Colombia [13] and Trinidad and Tobago [16], they differ from what has been reported for women from Brazil [29, 30] and Mexico [31]. The reason for these discrepancies is not immediately evident but could be due to differences to where countries are in the nutrition transition, other population characteristics, or study methodology. In any case, the inconsistent findings for both energy-dense food intake and excess body weight mirror those previously reported for US and Canadian groups [12, 25, 28].

The present study has several potential limitations that should be considered when interpreting its findings. For example, the cross-sectional study design allows for inference 
but not establishment of temporal or causal effects. Since nonprobabilistic sampling was used that may not be representative of women living in other areas of Quito, those without children, or those with other characteristics. Another potential limitation concerns the study timing and length of data collection. This was due to logistical considerations related to the research team schedules and availability at the study sites during summer months only. In addition, since the assessment of food security status was limited to the past 12 months, it may not be necessarily representative of household situations over a longer period of time. Furthermore, since the development of anemia and overweight/obesity in women may take longer than 12 months covered in the food security survey instrument, we were forced to infer about past food security status. This was especially true for our assumption about short adult stature which usually results from undernutrition and other environmental insults (e.g., infection) that occur earlier in life during critical child and adolescent growth periods. For these reasons, it is suggested that future studies employ a longitudinal study design to simultaneously track HFI and nutritional indicators over time to confirm these relationships. It is also possible that, in some cases, the food security status of a household did not reflect that of a woman living in the same home as the findings from some studies suggest that the intrahousehold distribution of food and other resources may not always be equitable [59].

Ecuador has been making a concerted effort to improve the food, nutrition, and health of women, children, and other vulnerable subgroups. The new 2008 constitution guaranteed the rights of citizens to food and nutrition security, health, and other social protections. The Ecuadorian government, under its Buen Vivir National Development Plan, has identified specific nutrition and health priorities, goals, and action plans [60]. During the past decade, it substantially increased spending on its cash transfer, school feeding, nutrition education, maternal-child health, and other social safety net programs designed to reduce poverty and improve the quality of life [61]. Ecuador also has enacted new regulations on school meals and physical activity and recently implemented a mandatory requirement that all processed foods carry a "traffic light" label in traffic light color used to clearly indicate levels of fats, sugar, and salt in the item [62]. Ecuador also has banned the use of friendly animal characters, cartoon personalities, and celebrities for advertising foods and beverages with a high-fat, sugar, and salt content and is considering a new tax on "junk food" to reduce consumption and generate funding for antiobesity programs.

However, improving the food insecurity situation of Ecuadorian households requires that policy and program planners know where the most vulnerable households live are located and understand which factors promote and protect against it. We recommend that systematic surveillance be implemented in order to better target, monitor, and evaluate the outcomes of local and national food and nutrition security policies and programs for vulnerable Ecuadorian households. This requires the regular collection of up-to-date and disaggregated data.
We recommend using an experience-based instrument for surveillance purposes and research studies and other studies because these best capture the multiple quantitative and qualitative dimensions of food insecurity. The languageadapted experiential food security instrument used in this study exhibited good validity and reliability for the urban Quito households. However, investigators may also want to undertake validation of the Latin American and Caribbean Food Security Scale (Escala Latinoamericana y Caribeña de Seguridad Alimentaria) or the new FAO Food Insecurity Experience Scale (FIES) [63] for use in Ecuador since the use of harmonized, experience-based food insecurity measurement instruments would facilitate within- and betweenpopulation comparisons. In addition, the FIES instrument can be used for either household or individual level food security assessment [63].

\section{Disclosure}

M. Margaret Weigel and Rodrigo X. Armijos former institution is as follows: Department of Public Health Sciences, College of Health Sciences, University of Texas at El Paso (UTEP), USA.

\section{Competing Interests}

The authors declare that they have no competing interests.

\section{Acknowledgments}

The study was funded, in part, by the UTEP Minority Health International Research Training Program (MHIRT), Secretaría Nacional de Educación Superior, Ciencia, Tecnología e Innovación (Programa Prometeo), and Universidad Central del Ecuador. The authors also gratefully acknowledge the study participants and the excellent technical assistance provided by Quito school and public health clinic personnel, UTEP MHRIT Program students, and Universidad Central del Ecuador postgraduate medical residency students.

\section{References}

[1] United Nations. Department of Economic and Social Affairs. Population Division, "World urbanization prospects: the 2014 revision," Tech. Rep. ST/ESA/SER.A/366, 2015, http://esa.un .org/unpd/wup/Publications/Files/WUP2014-Report.pdf.

[2] United Nations Development Programme Human Development Report, 20th Anniversary Edition, The Real Wealth of Nations: Pathways to Human Development, 2010, http://hdr .undp.org/en/media/HDR_2010_EN_Complete_reprint.pdf.

[3] Food and Agriculture Organization, "Final Report on World Food Security," CFS 2012/39, 39th Session Rome, Italy, 2012, http://www.fao.org/bodies/cfs/cfs39/en/.

[4] M. T. Ruel, "Is dietary diversity an indicator of food security or dietary quality? A review of measurement issues and research needs," Food and Nutrition Bulletin, vol. 24, no. 2, pp. 231-232, 2003.

[5] P. Mirmiran, L. Azadbakht, and F. Azizi, "Dietary diversity within food groups: an indicator of specific nutrient adequacy in 
Tehranian women," Journal of the American College of Nutrition, vol. 25, no. 4, pp. 354-361, 2006.

[6] E. W. Kimani-Murage, L. Schofield, F. Wekesah et al., "Vulnerability to food insecurity in urban slums: experiences from Nairobi, Kenya," Journal of Urban Health, vol. 91, no. 6, pp. 10981113, 2014.

[7] W. J. Garvelink and K. Wedding, Nutrition and Food Security in the City, Center for Strategic and International Studies, Washington, DC, USA, 2013, http://csis.org/publication/nutrition-and-food-security-city.

[8] C. Tacoli, B. Bukhari, and S. Fisher, Urban Poverty, Food Security and Climate Change, Human Settlements, Working Paper no. 37, International Institute for Environment and Development, London, UK, 2013, http://pubs.iied.org/pdfs/10623IIED.pdf.

[9] C. B. Barnett, Food Security and Sociopolitical Stability, Oxford University Press, 2013.

[10] M. Fay, The Urban Poor in Latin America, World Bank, Washington, DC, USA, 2005.

[11] A. Coleman-Jensen, M. P. Rabbitt, C. Gregory, and A. Singh, Household Food Security in the United States in 2014, ERR-194, U.S. Department of Agriculture, Economic Research Service, 2015.

[12] Institute of Medicine, Hunger and Obesity: Understanding a Food Insecurity Paradigm: Workshop Summary, The National Academies Press, Washington, DC, USA, 2011.

[13] S. Isanaka, M. Mora-Plazas, S. Lopez-Arana, A. Baylin, and E. Villamor, "Food insecurity is highly prevalent and predicts underweight but not overweight in adults and school children from Bogotá, Colombia," Journal of Nutrition, vol. 137, no. 12, pp. 2747-2755, 2007.

[14] M. Hackett, H. Melgar-Quinonez, and M. C. A. Uribe, "Internal validity of a household food security scale is consistent among diverse populations participating in a food supplement program in Colombia," BMC Public Health, vol. 8, article 175, 2008.

[15] M. C. Álvarez-Uribe, A. Estrada-Restrepo, and Z. Y. FonsecaCenteno, "Characterising colombian households regarding quality of life-based food insecurity," Revista de Salud Publica, vol. 12, no. 6, pp. 877-888, 2010.

[16] M. C. Gulliford, D. Mahabir, and B. Rocke, "Food insecurity, food choices, and body mass index in adults: nutrition transition in Trinidad and Tobago," International Journal of Epidemiology, vol. 32, no. 4, pp. 508-516, 2003.

[17] N. C. Fischer, T. Shamah-Levy, V. Mundo-Rosas, I. MéndezGómez-Humarán, and R. Pérez-Escamilla, "Household food insecurity is associated with anemia in adult Mexican women of reproductive age," Journal of Nutrition, vol. 144, no. 12, pp. 2066-2072, 2014.

[18] C. M. Chaparro, Household Food Insecurity and Nutritional Status of Women of Reproductive Age and Children under 5 Years of Age in Five Departments of the Western Highlands of Guatemala: An Analysis of Data from the National MaternalInfant Health Survey 2008-09 of Guatemala, FHI360/FANTA-2 Bridge, Washington, DC, USA, 2012.

[19] M. M. Weigel and M. M. Armijos, "Food insufficiency in the households of reproductive-age ecuadorian women: association with food and nutritional status indicators," Ecology of Food and Nutrition, vol. 54, no. 1, pp. 20-42, 2015.

[20] Pan American Health Organization (PAHO), Anemia in Latin America and the Caribbean, 2009: Situation Analysis, Trends and Implications for Public Health Programming, PAHO, Washington, DC, USA, 2009.
[21] R. J. Stoltzfus, "Iron interventions for women and children in low-income countries," Journal of Nutrition, vol. 141, no. 4, pp. 756S-762S, 2011.

[22] R. L. Bailey, K. P. West Jr., and R. E. Black, “The epidemiology of global micronutrient deficiencies," Annals of Nutrition and Metabolism, vol. 66, supplement 2, pp. 22-33, 2015.

[23] Pan American Health Organization (PAHO), Underweight, Short Stature and Overweight in Adolescents and Young Women in Latin America and the Caribbean, PAHO, Washington, DC, USA, 2011, http://www.paho.org/hq/index.php?option=com docman \& task $=$ cat_view \& gid $=3426 \&$ limit $=10$ \&limitstart $=0$ \& order $=$ date\&dir=DESC\&Itemid $=270 \&$ lang $=$ en.

[24] Food and Agriculture Organization (FAO), The State of Food Insecurity in the World 2012. Economic Growth is Necessary but Not Sufficient to Accelerate Reduction of Hunger and Malnutrition, Food and Agriculture Organization (FAO), Rome, Italy, 2012.

[25] B. Franklin, A. Jones, D. Love, S. Puckett, J. Macklin, and S. White-Means, "Exploring mediators of food insecurity and obesity: a review of recent literature," Journal of Community Health, vol. 37, no. 1, pp. 253-264, 2012.

[26] B. A. Laraia, "Food insecurity and chronic disease," Advances in Nutrition, vol. 4, no. 2, pp. 203-212, 2013.

[27] Q. G. To, E. A. Frongillo, D. Gallegos, and J. B. Moore, "Household food insecurity is associated with less physical activity among children and adults in the U.S. population," Journal of Nutrition, vol. 144, no. 11, pp. 1797-1802, 2014.

[28] N. I. Larson and M. T. Story, "Food insecurity and weight status among U.S. children and families: a review of the literature," American Journal of Preventive Medicine, vol. 40, no. 2, pp. 166173, 2011.

[29] G. Velásquez-Melendez, M. M. Schlüssel, A. S. Brito, A. A. M. Silva, J. D. Lopes-Filho, and G. Kac, "Mild but not light or severe food insecurity is associated with obesity among Brazilian women," Journal of Nutrition, vol. 141, no. 5, pp. 898902, 2011.

[30] M. M. Schlüssel, A. A. M. da Silva, R. Pérez-Escamilla, and G. Kac, "Household food insecurity and excess weight/obesity among Brazilian women and children: a life-course approach," Cadernas de Saúde Pública, vol. 29, no. 2, pp. 219-226, 2013.

[31] M. C. Morales-Ruán, I. Méndez-Gómez Humarán, T. ShamahLevy, Z. Valderrama-Álvarez, and H. Melgar-Quiñónez, "Food insecurity is associated with obesity in adult women of Mexico," Salud Publica de Mexico, vol. 56, supplement 1, pp. s54-s61, 2014.

[32] Instituto Nacional de Estadisticas y Censos, "Proyeccion Provincias, Sexos y Areas 2010-2020," 2010, http://www.ecuadorencifras.gob.ec/proyecciones-poblacionales/.

[33] W. B. Freire, M. J. Ramirez-Luzuriaga, P. Belmont et al., Tomo I: Encuesta Nacional de Salud y Nutrición de la Población Ecuatoriana de Cero a 59 Anos. ENSANUT-ECU 2012, Ministerio de Salud Pública, Instituto Nacional de Estadística y Censos, Quito, Ecuador, 2014.

[34] W. B. Freire, K. M. Silva-Jaramillo, M. J. Ramirez-Luzuriaga, P. Belmont, and W. F. Waters, "The double burden of undernutrition and excess body weight in Ecuador," American Journal of Clinical Nutrition, vol. 100, no. 6, pp. 1636S-1643S, 2014.

[35] Pan American Health Organization (PAHO), Ultra-Processed Food and Drink Products in Latin America: Trends, Impact on Obesity, Policy Implications, PAHO, Washington, DC, USA, 2015. 
[36] Ministerio de Salud Publica (MSP), Indicadores Básicos de Salud Ecuador 2011, MSP, Quito, Ecuador, 2012, http://www2 .paho.org/ecu/dmdocuments/indi_bs_\%202011.pdf.

[37] M. Hackett, A. C. Zubieta, K. Hernandez, and H. MelgarQuiñonez, "Food insecurity and household food supplies in rural Ecuador," Archivos Latinoamericanos de Nutricion, vol. 57, no. 1, pp. 10-17, 2007.

[38] M. M. Weigel, R. X. Armijos, M. Mayorga, and G. Guitierrez, "Household food security, hunger, and dietary diversity and quality in rural farming communities in the Ecuadorian High Andes," in Proceedings of the 140th Annual Meetingof the American Public Health Association, \#270007, October 2012, https:// apha.confex.com/apha/140am/webprogram/Paper270007.html.

[39] United Nations Environmental Program (UNEP), Urban Air Pollution, http://www.unep.org/urban_environment/issues/urban_air.asp.

[40] B. Villacís and D. Carrillo, Estadística Demográfica en el Ecuador: Diagnóstico y Propuesta, Instituto Nacional de Estadística y Censos (INEC), Quito, Ecuador, 2011.

[41] Municipio del Distrito Metropolitano de Quito (QMD)/Secretaria Metropolitana de Salud, Plan Estratégico 2015-2025, QMD, Quito, Ecuador, 2015.

[42] Municipio del Distrito Metropolitano de Quito. Plan de Desarrollo 2012-2022, 2011, http://www.emaseo.gob.ec/documentos/ lotaip_2012/s/plan_de_desarrollo_2012_2014.pdf.

[43] B. Villacris, "El 35\% de los Habitantes de Quito son Inmigrantes Internos," El Comercio, 2011, http://www.elcomercio.com/ actualidad/quito/35-de-habitantes-de-quito.html.

[44] United Nations High Commissioner for Refugees (UNHCR) and Instituto de la Ciudad, Urban Profiles of the Colombian Population in Quito. Refugees, Asylum Seekers and Other Migrants, 2011, http://www.jips.org/system/cms/attachments/ 816/original_UrbanProfilesQuito_Summary.pdf.

[45] Instituto Nacional de Estadística y Censos (INEC), Encuesta Nacional de Empleo, Desempleo y Subempleo (ENEMDU) Indicadores de Pobreza y Desigualdad, Marzo 2015, http://www .ecuadorencifras.gob.ec/pobreza/.

[46] G. G. Harrison, A. Stormer, D. R. Herman, and D. M. Winham, "Development of a Spanish-language version of the U.S. household food security survey module," Journal of Nutrition, vol. 133, no. 4, pp. 1192-1197, 2003.

[47] USDA, U.S. Household Food Security Survey Module: ThreeStage Design, with Screeners, Economic Research Service, USDA, Washington, DC, USA, 2012, http://www.ers.usda.gov/ topics/food-nutrition-assistance/food-security-in-the-us/survey-tools.aspx\#household.

[48] C. Gregory, T. Smith, and M. Wendt, "How Americans rate their diet quality: an increasingly realistic perspective," USDA Economic Research Service Economic Information Bulletin 83, 2011.

[49] R. S. Gibson, Principles of Nutritional Assessment, Oxford University Press, London, UK, 2nd edition, 2005.

[50] Food and Agriculture Organization, Guidelines for Measuring Household and Individual Dietary Diversity, Food and Agriculture Organization (FAO), Rome, Italy, 2010, http://www .fao.org/docrep/014/i1983e/i1983e00.pdf.

[51] World Health Organization, "Body Mass Index BMI," http:// www.euro.who.int/en/health-topics/disease-prevention/nutrition/a-healthy-lifestyle/body-mass-index-bmi.

[52] S. M. Grundy, J. I. Cleeman, S. R. Daniels et al., "Diagnosis and management of the metabolic syndrome: an American
Heart Association/National Heart, Lung, and Blood Institute Scientific Statement," Circulation, vol. 112, no. 17, pp. 2735-2752, 2005.

[53] WHO, Haemoglobin Concentrations for the Diagnosis of Anaemia and Assessment of Severity. Vitamin and Mineral Nutrition Information System, (WHO/NMH/NHD/MNM/11.1), World Health Organization, Geneva, Switzerland, 2011, http://www.who.int/vmnis/indicators/haemoglobin.pdf.

[54] La Secretaría de Ambiente/Red Metropolitana de Monitoreo Atmosférico (REMMAQ) red Metropolitana de Monitoreo Atmosférico (REMMAQ), http://www.quito.gob.ec/index.php/ quito-por-temas/ambiente.

[55] World Health Organization (WHO), "BMI classification," 2010, http://apps.who.int/bmi/index.jsp?introPage=intro3.html.

[56] K. K. Schmeer, B. A. Piperata, A. H. Rodríguez, V. M. S. Torres, and F. J. C. Cárdenas, "Maternal resources and household food security: evidence from Nicaragua," Public Health Nutrition, vol. 18, no. 16, pp. 2915-2924, 2015.

[57] M. Hackett, H. Melgar-Quiñonez, C. A. Taylor, and M. C. A. Uribe, "Factors associated with household food security of participants of the MANA food supplement program in Colombia," Archivos Latinoamericanos de Nutricion, vol. 60, no. 1, pp. 42-47, 2010.

[58] International Vitamin A Consultative Group (IVACG), Vitamin $A$ and Iron Interactions, IVACG Secretariat, ILSI Research Foundation, Washington, DC, USA, 1998.

[59] C. Brunelli and S. Viviani, Exploring gender-based disparities with the FAO Food Insecurity Experience Scale. Statistics Division, Food and Agriculture Organization, 2014, http:// unstats.un.org/unsd/gender/Mexico_Nov2014/Session\%201\%20 FAO\%20paper.pdf.

[60] Secretaría Nacional de Planificación y Desarrollo Ecuador (SENPLADES), Plan Nacional de Desarrollo/Plan Nacional para el Buen Vivir 2013-2017, SENPLADES, Quito, Ecuador, 2013, http://www.buenvivir.gob.ec/.

[61] World Bank, The State of Social Safety Nets 2015, World Bank, Washington, DC, USA, 2015, http://documents.worldbank.org/ curated/en/2015/07/24741765/state-social-safety-nets-2015.

[62] Consumers International, "World Consumer Rights Day 2015: Consumers Rights to Healthy Food Briefing no. 4, Nutrition 27 labelling on pre-packaged foods," http://www.consumersinternational.org/our-work/wcrd/.

[63] T. J. Ballard, A. W. Kepple, and C. Cafiero, "The food insecurity experience scale: development of a global standard for monitoring hunger worldwide," Tech. Rep., FAO, Rome, Italy, 2013, http://www.fao.org/economic/ess/ess-fs/voices/en/. 


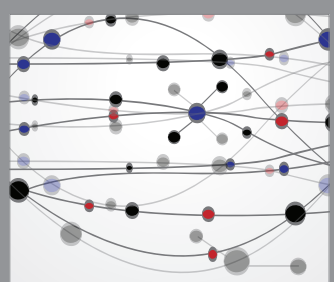

The Scientific World Journal
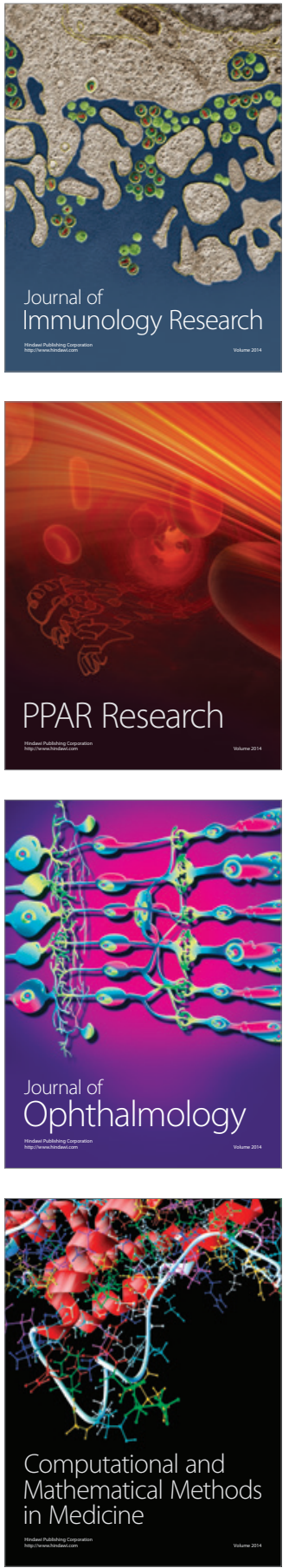

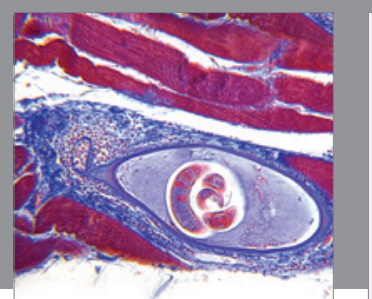

Gastroenterology Research and Practice

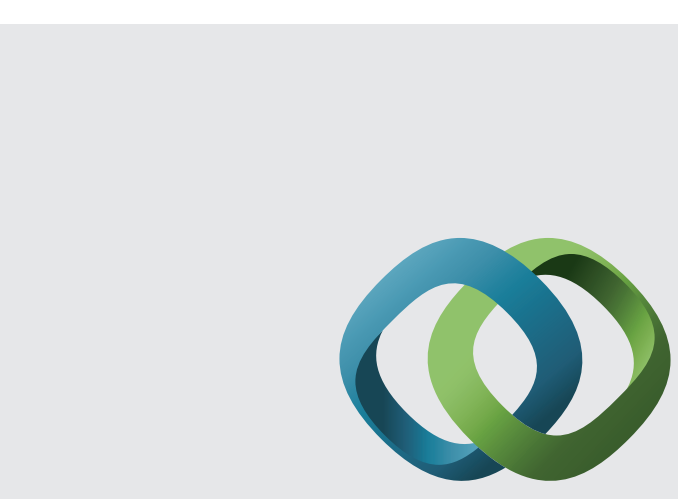

\section{Hindawi}

Submit your manuscripts at

http://www.hindawi.com
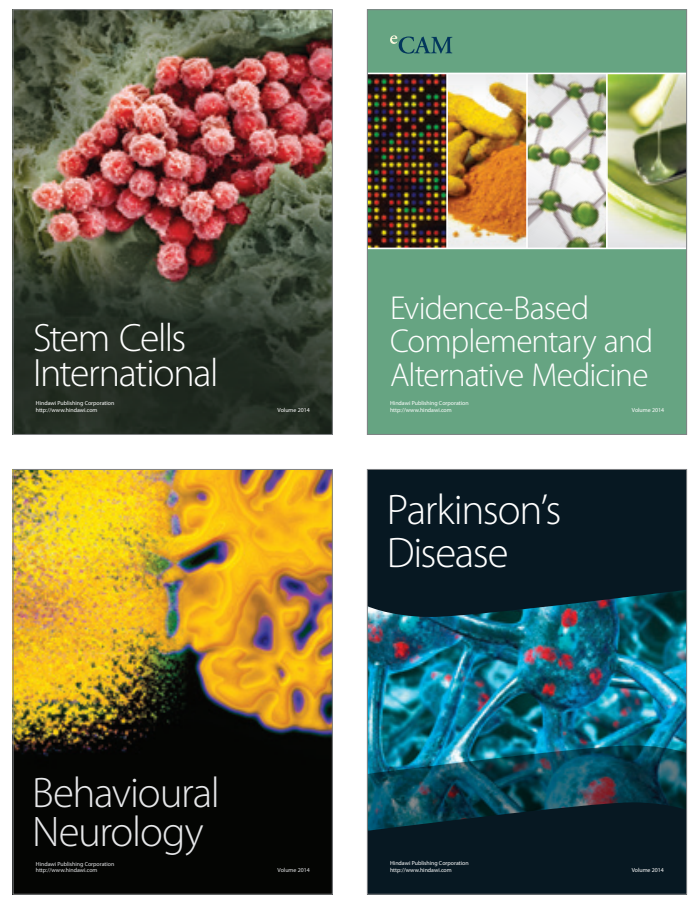
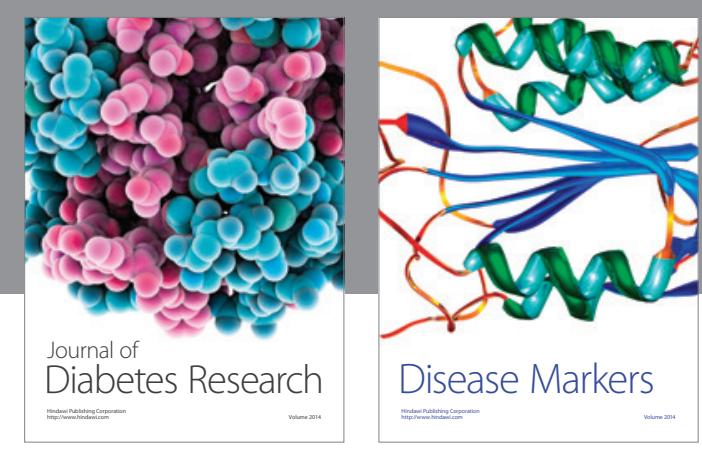

Disease Markers
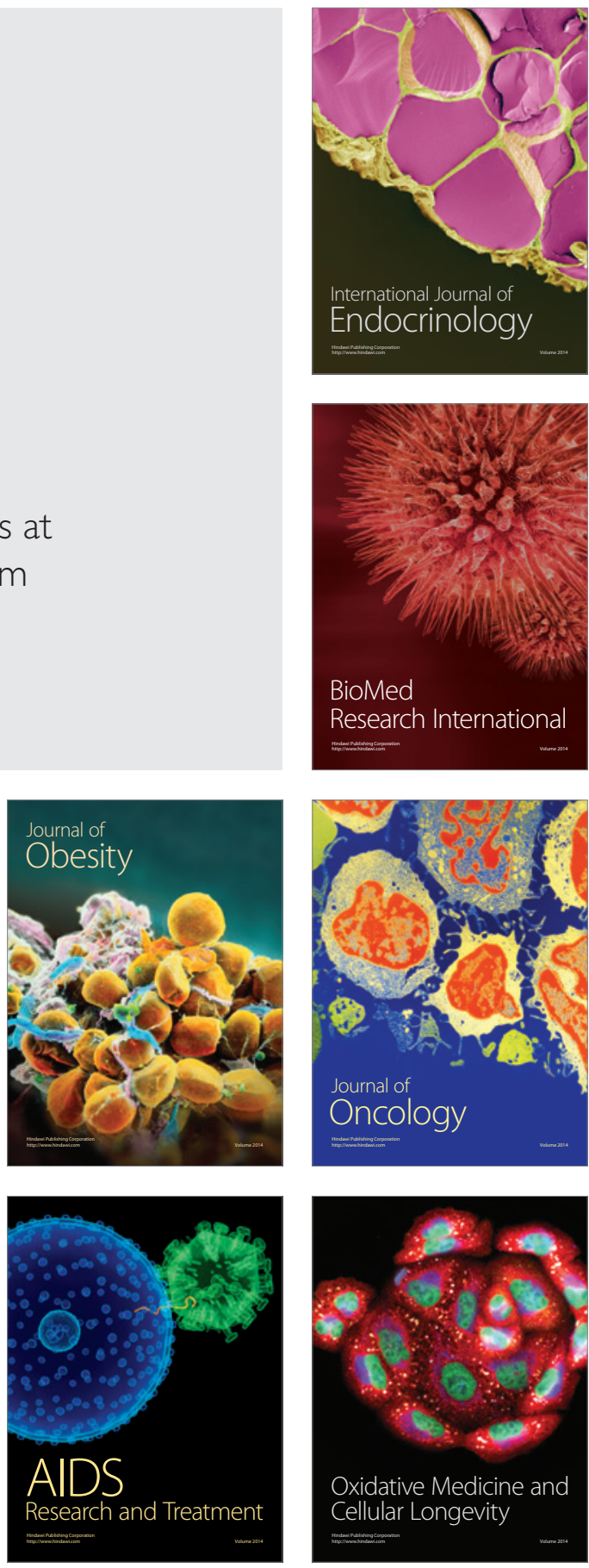